\title{
Beyond normative ethics: Ethics of arts-based disability research
}

Roxanne Mykitiuk

York University

A. Chaplick

York University

Carla Rice

University of Guelph

This work is licensed under the Creative Commons Attribution-NonCommercialNoDerivatives 4.0 International License. To view a copy of this license, visit http://creativecommons.org/licenses/by-nc-nd/4.0/ or send a letter to Creative Commons, PO Box 1866, Mountain View, CA 94042, USA.

Recommended citation:

Mykitiuk. R., Chaplick, A., \& Rice, C. (2015). Beyond normative ethics: Ethics of disability arts research. Ethics, Medicine, and Public Health, 1(3), 373-382. https://doi.org/10.1016/i.jemep.2015.07.005 


\section{Beyond normative ethics: Ethics of arts- based disability research}

Roxanne Mykitiuk, Amy Chaplick, Carla Rice

\section{Summary}

In Western culture, the pervading medical model of disability has characterized disability as a problem in need of a solution: an unwanted condition that demands a cure. Even the word "disability" is unavoidably negative: structurally it signifies a loss or a lack, a state that exists only because it falls short of something better. Contrary to mainstream thinking, disability is not a natural state of inferiority or a stroke of misfortune; rather, disability is a culturally fabricated narrative of embodiment. As Scully (2008) observes, representations of disability, created in the main by nondisabled people, tell normative bodies what they want to know - or think they want to know about non-disabled people. Arts-based mediums have the potential to effect positive change and alter prevailing perceptions of embodiment. Disability arts provide individuals living with disabilities with opportunities to communicate their perspectives in sustainable ways and speak back to culturally dominant images and stories. One such initiative, Project Re $\cdot V i s i o n$, uses the power of arts-informed research to tell stories from the position and leadership of those who embody difference. In doing so, the project seeks to challenge conventional understandings of disability as an ailment to be cured. Although much academic discussion has focused on arts-informed research ethics, there has been little consideration of the ethics of conducting "disability" arts-informed research. Our paper will therefore explore what is distinct about disability arts- 
informed research, as well as the unique ethical issues that arise when working with non-normative bodies.

\section{Keywords}

Disability research ethics; Arts-based research ethics; Embodied difference; Digital storytelling; Research-based drama

\section{Introduction}

The representational history of people with disabilities and body/mind differences can largely be characterized as one of being put on display or hidden away ([1] p 514). Medicalized conceptions of disability and $\mathrm{mind} /$ body difference have retained a powerful influence on the public's perceptions, shaping negative attitudes towards disabled people. The stigmatized connotations of inadequacy, deficit, and dependency continue to form the background to the stereotypical ways that society understands disabled people's lives ([2] p 25).

In insidious and pervasive ways, including interactional and representational ways, our culture is taught that people with disabilities live unlivable lives ([1] p 524). Individuals who live in and with different embodiments are taught to normalize themselves, apologize for their differences, or live uninhabitable embodiments ([1] p 524). Bioethicist Scully [3] thus advocates for the creation of "reconstructive narratives" that seek to revalue the particularities we think of as impairment and deviance. Such narratives, she suggests, have the potential to disrupt conventional understandings of normalcy and generate new ways of thinking about variant bodies/minds ([3] p 115). 
Arts-based initiatives have increasingly been regarded as a promising way to create and center, without normalizing, representations of individuals who have previously been relegated to the margins. ${ }^{1}$ Project Re・Vision, a ClHR (Canadian Institutes for Health Research) funded initiative, uses the arts-based research methods of digital storytelling and drama to tell stories from the position and leadership of those who embody difference. In doing so, we strive to challenge conventional understandings of disability as an ailment to be cured, eliminated or overcome.

Like any research method, though, ethical issues must be considered when using arts-based research methods as a tool for public engagement and perceptual change. To date, literature in the field has been primarily concerned with the content and form of arts-based research ([4] pp 1-2). Ethical questions and considerations have either been neglected or limited to the arts-based health research context ([4] pp 1-2). Consequently, there has been little consideration of the ethics of conducting arts-based "disability" research. Our paper seeks to address this significant gap in the literature by introducing and theorizing what is distinct about disability artsbased research, as well as the unique ethical issues that arise when working with non-normative bodies/minds. We explore these ethical conundrums through a disability studies lens, drawing on both the existing literature and our own experiences with Project Re $\bullet$ Vision digital storytelling workshops and research-based drama, Small Acts of Saying. In doing so, we hope that researchers and practitioners using a variety of arts-based methods will benefit from a deeper consideration of the issues reviewed.

\footnotetext{
${ }^{1}$ In this paper, we use the pronoun "we" primarily to refer to ourselves as authors and as Project $\mathrm{Re} \cdot \mathrm{Vision}$ facilitators and participants.
} 


\section{Defining disability}

Disability is an overarching, and in some ways, artificial category that encompasses an exceedingly diverse group whose only commonality is being considered "abnormal" ([2] p 24). Because disability is defined not as a set of observable, predictable traits but rather as any departure from an unstated physical and functional norm, disability highlights individual differences ([2] p 24). Thinking about disability is profoundly difficult; any concept of disability has to cope with the vast heterogeneity of impairment, as well as a highly contested understanding about what is actually disabling ([3] $p 2)$.

Historically, the pervading medical model of disability has characterized disability as a condition that demands a cure. The key feature of a medicalized view of disability is that non-normative bodies/minds are an abnormality of form or function, the cause of which lies within the biology of the individual ([3] p 23). Under this framework, disability is viewed as a "personal tragedy"? [5] and is thought to confer pain, disease, suffering, dependence, and to limit life opportunities and quality ([6] p 340).

In contrast to the medical model of disability, the strong social model suggests that disability is a product of the interaction, at personal and structural levels, between physical or mental anomaly and the social world in which an individual lives ([3] p 25). In this model, disability is not an intrinsic, individualized property of the body, but rather a result of societal

\footnotetext{
2 In the 1980s, Michael Oliver (1983) discussed a social - as opposed to individual - model of disability. He suggested that a "personal tragedy theory" of disability underpins the individual model and involves the medicalization, and concomitant individualizing, of the effects of living with impairment. For more information, see [5].
} 
and cultural barriers that impose restrictions upon disabled people ([3] p 25, [7] p 94). Though profoundly transformative in its impacts on the lives of many disabled people, the strong social model has been criticized from within and beyond disability studies ([3] p 26). This framework establishes a false dichotomy that is not tenable between impairment and disability whereby the former (the physical, intellectual, sensory, psychological difference) is separated from the latter (social restrictions imposed upon individuals with impairments) ([5] p 69). This dualist approach reinforces the traditional Cartesian mind/body split that runs through medical and other scientific discourses ([5] p 69). Bioethicist Scully [3] has argued that the strong social model's dismissal of the impaired body from disability studies scholarship effectively concedes it to biomedicine: if socialrelational approaches have nothing to say about impairment, then biomedicine will have everything to say about it ([3] p 29).

Other social-relational approaches have been more inclined toward engaging with subjective experience and the representation of the impaired body ([3] p 29). Feminist disability theorists have been foremost in resisting attempts to "separate the domains of private experience and public oppression," arguing that such a dichotomy leads to a substantial depletion of disability theory ([3] p 29). The informing premise of feminist disability theory is that disability, like femaleness, is not a natural state of corporeal inferiority, inadequacy, or a stroke of misfortune; rather, disability, like gender is a culturally fabricated narrative of the body ([8] p 5). As GarlandThomson explains, the disability/ability system produces subjects by differentiating and marking bodies ([8] pp 5-6). A Derridean perspective on disability would argue that though they are antagonistic, normativism needs 
disability for its own definition; an individual without an impairment can define him or herself as "normal" only in opposition to that which he or she is not - an individual with an impairment ([5] p 65). In this way, disability is not excluded from normativism: it is integral to its very assertion.

According to Garland-Thomson [2] since most of us, if we live long enough, will undergo the gradually disabling process of aging, disability should not be seen as exclusive to a small number of people but rather, as a central part of the human condition. More than this, the desire to frame non-normativity predominantly as deficiency and to rid the world of disability denies that many disabled people live vital and dynamic lives and many of us, disabled and non-disabled people, desire disability. For these reasons, it is critical that we examine how disability is typically storied and how disability studies and disabled people story disability differently.

\section{(Re) Thinking disability}

Titchkosky [9] has argued that disability is an "imagined form of embodiment": individuals never come to think about and perceive disability "purely"; rather, disability is always steeped in the collective cultural act of interpretation ([9] p 76). While there is no one correct representation of disability, there are distinct representations of embodied difference in Western culture and impairment narratives that appear in literature, cinema, and theater ([3] p 117, [9] p 76). Among the most prominent associated identities are the "tragic victim; the hero overcoming the odds (the supercrip); the saintly sage; the sweet angel; the comic; the contaminant; the burden to society and family; and the evil or obsessive avenger, psychologically or morally warped by impairment" ([3], p 117). As Scully [3] explains, these "master narratives" of disability shape our moral 
imaginations and prescribe individuals' behaviors, values, and life trajectories because of their staying power and epistemological authority ([3] p 112). Master narratives of impairment tell non-disabled people what they know, or think they want to know, about impairment ([3] p 117). Countered by few mitigating narratives, dominant representations of impairment often misrepresent, simplify, or flatten the experience individuals have of their own or others' disabilities ([2] pp 10-12).

In his essay Stolen Bodies, Reclaimed Bodies, disabled poet and essayist Clare [10] writes, "just as the [disabled] body can be stolen, it can also be reclaimed." To accomplish this, Scully advocates for the creation of "reconstructive narratives" that provide alternative and morally less harmful accounts of non-normative bodies. Through counter stories, damaging portrayals of disability, can be replaced by narratives that are entirely missing from the existing repertoire ([3] p 128). The end ethical goal is to disrupt conventional understandings of normalcy and generate new ways of thinking about non-normative bodies.

\section{Disability and the arts \\ Disability arts}

One pathway for constructing counter stories of impairment is through arts-based initiatives. This follows a vibrant disability arts movement that has garnered attention as a new genre that aims to give expression to disability experience and re-imagine bodily difference. In the Anglo-western world, the disability arts movement grew out of the disability rights movement of the late 1970s [11] and marked a shift in disability activism away from securing legal rights for persons with disabilities to focusing on aesthetic/cultural concerns about the representation of non-normative 
bodies. Since then, the arts have emerged as an important site of activism for inclusion, as a "force that draws people into participation," and a political vehicle for centering "normally silenced or disenfranchised voices ([12] $p$ 518)." Through disability arts, individuals with disabilities have opportunities to communicate their perspectives and speak back to culturally dominant images and stories.

Disability arts have the ability to make a political difference where other forms of ideological critique fail ([13] p 32). This is because disability artists frequently use their own bodies as the medium to subvert and undermine disabling barriers ([13] p 32). This embodied display of difference greatly contrasts the strong social model of disability that separates the impaired body from the disability experience ([12] p 518). The embodied nature of disability art therefore offers a unique educative and transformative experience for its audience to examine their own attitudes towards disability ([13] p 32).

\section{Arts-based research}

Arts-based research is the systematic use of the artistic process and artistic expression - as a primary way of understanding and examining experience ([14] p 29). In a variety of contexts, it seeks to uncover and/or produce, and disseminate and/or translate, experiential and theoretical knowledge ([15] p 127). Studies suggest that arts-based methods are more engaging and empowering than traditional qualitative methods ([16] para 1) by enhancing the well-being and creativity of participants and contributing to the building of community ([16] para 21).

A review of the literature indicates that arts-based methods have increasingly been used in the health care context ([17] $p$ 7), particularly with 
participants who have serious and life-threatening illnesses ([15] p 138). Many of these research initiatives strive to raise critical awareness of health-related issues and allow both participants and audiences to understand experiences of illness ([16] para 14), in ways that words alone cannot elucidate ([15] p 138).

Although less prominent in the literature, arts-based "disability" research has also become a powerful medium for effecting positive change and altering prevailing perceptions of embodiment. One such initiative, Project Re $\cdot$ Vision, is a mobile multi-media lab and expressive arts institute dedicated to exploring ways that communities can use arts-based research to advance social inclusion and justice by challenging stereotypes.

$\mathrm{Re} \cdot V i s i o n$ uses the power of arts-based research to tell stories from the position and leadership of those who embody difference, and creates space to open dialogue about these representations and their new meanings.

Responding to Scully's call for counter stories of disability [3], Project $\mathrm{Re} \cdot \mathrm{Vision}$ makes use of the narrative and visually-oriented medium of digital storytelling to create and exchange knowledge. Digital stories are two to three-minute films that pair audio recordings of first-person narratives with visuals (including photographs, video clips, and artwork). Studies show that digital storytelling can assist storytellers in giving voice to previously unspoken experiences, including cultural silences and social exclusions, through image, symbol, and metaphor [18]. By making the implicit explicit, digital storytelling become a powerful device for generating awareness, enhancing agency, and creating and strengthening communities [1], [19]. Through digital storytelling, individuals make 
meaning of experiences on their own terms, communicate perspectives that open dialogue, and take the power back by escaping the confines of culturally dominant images and messages [20], [21].

In addition to digital storytelling, $\mathrm{Re} \cdot \mathrm{Vision}$ employs the genre of drama as a means of investigating, representing, and disseminating aspects of our research. Through drama, arts-inspired social research has the potential to reach wider and more diverse audiences than traditional scholarly research ([14] p 485). Drama has the capacity to cultivate empathy and reasoned critique ([22] p 1473), as well as to engage individuals of diverse perspectives, both emotionally and cognitively, in a form that does the stories "better justice ([23] p 32)."In their analysis of I'm Still Here, Mitchell et al. [24] concluded that drama is an effective way to translate research and to provoke change in understanding with its potential to enhance visibility, passion, and insight ([24] p 390). Together, then, digital storytelling and drama make space for improvisation, creativity, sensory pleasure, and beauty in and of difference, and hence, for remaking the once abject into an embodied, even celebrated, identity.

The ethics of arts-based research

Like any research method, ethical issues must be considered when using arts-based research methods as a tool for public engagement. In both a health and disability context, these issues range from privacy and anonymity concerns to potential negative consequences of asking individuals to communicate intimate experiences in an embodied and a representational manner. It is generally agreed that human research is grounded in the fundamental values of respect, research merit and integrity, justice, and beneficence ([25] p 7). These values inform both 
"procedural ethics" (research ethics approvals), and "ethics in practice" (issues not anticipated in the approval process) ([25] p 7). Arts-based research also uniquely requires its researchers to rethink how to respond to ethical issues.

Cox et al. [25] identified six interrelated ethical categories when using visual research methods: confidentiality; minimizing harm; consent; fuzzy boundaries (the blurring of roles between researchers, participants, and artists); authorship and ownership; and representation and audience ([25] p 8). Dush [26] notes that digital storytelling raises several unique questions including whether there are dangers in appropriating someone else's story if they are not given control at all moments and whether it is ethical to include (without consent) images of others captured in one's personal photographs ([26] p 631). Accordingly, as Gubrium et al. [27] contend, to ethically resolve these issues, both process (safer and meaningful workshop experience for participants) and end products (digital videos) must be seriously considered ([27] e 8).

Drama-based research raises distinct ethical issues, such as balancing aesthetic urges and data integrity ([28] p 452) and anticipating harm to individuals witnessing the representations ([29] p 462). Sinding et al. [29] note that when conducting drama-based research, researchers must always be mindful of who and how individuals are represented, and how such representations reinforce or challenge the broader cultural stories that are told about a situation, an action, or a group of people ([29] p 34). Researchers must be aware that the participants' stories and lives become "audible, visible, felt by them in visceral and potentially lasting ways ([29] $p$ 465)." They must therefore respect the sensibilities of the people 
represented. For Sinding et al. [29], this does not mean there must be only "feel-good" representations; rather, researchers should enable the individuals and communities represented to engage with the art before it goes public ([29] p 465).

\section{The ethics of arts-based (disability) research}

Ethical dilemmas are inevitable when conducting research with "vulnerable" populations; particularly those relating to research governance, interpretation, representation, confidentiality, and consent ([30] p 120). To ensure research participants are not put at further risk of harm or made even more vulnerable, Aldridge [30] stresses the strict adherence to ethical regulations and procedures ([30] p 114). Despite adherence to these policies, Aldridge acknowledges that some of these dilemmas will persist ([30] p 121).

When conducting arts-based disability research, researchers must be attuned to the historical framework in which they are working. People with disabilities have been put on display in medical journals, charity campaigns, and in freak shows [2]. At the same time, they have been hidden away from the public, in institutions, hospitals, and group homes ([1] p 514). Arts-based disability research brings additional and complex ethical questions that are distinct from a health context. These include:

- how researchers can create space for accessibility;

- how researchers might navigate encounters with fuzzy boundaries;

- what the ethical implications of research that generates complicated staring dynamics might be;

- and how a researcher might mitigate the potential for misrepresentation of participants. 
The remainder of this paper will explore these issues, drawing on both the existing literature and our own experiences with Project Re•Vision's digital storytelling workshops and research-based drama, Small Acts of Saying.

\section{Ethics in practice}

\section{Creating space for accessibility}

Creating space for accessibility requires researchers to consider the term accessibility in every sense of the word. At Re•Vision, researchers strive to make workshops open to everyone, following the assertion that "everyone can make a digital story." Accessibility guidelines and communication with participants (before, during and after the workshops) of what would make the workshop space more accessible and comfortable helps us to ensure an accessible space.

Despite our best efforts, we acknowledge that accessibility cannot always be fully achieved. We are not always able to anticipate how workshop room conditions can affect participants, such as flickering fluorescent lights that can cause migraines; how hiring sign language interpreters during workshop hours is not sufficient to ensure the full inclusion of $\mathrm{d} /$ Deaf storytellers; and how hierarchies of disability can get reproduced such as those between individuals with physical and intellectual disabilities ([1] p 523).

Beyond structural accessibility, it is also critical for researchers to consider emotional accessibility. Digital storytelling, for instance, can be used to share rich and personal imagery, allowing researchers to access personal spaces that would not normally be shared in other forms of research ([25] p 11). Reconstructing stories on sensitive topics, through 
evocative imagery and drama, has the potential to cause emotional harm from reliving events ([25] p 11). It can be unexpectedly confronting for some participants to have a visual record or embodied representation of their feelings, which they may later regret sharing ([25] p 11). When participants engage in a creative activity, they may feel exposed and vulnerable to criticism, especially when their work is shown to an external and unknown audience ([25] p 11). All of this can result in uncomfortable or unexpected feelings for those involved, leaving storytellers, and researchers, vulnerable ([4] p 11).

Here, researchers also make themselves vulnerable when sharing something about themselves to shed light on the subject in discussion, taking them somewhere they would not otherwise get to ([1] p 521). Being a vulnerable researcher means being present and honest with ourselves throughout our work, namely with our contradictory, unresolved, or difficult thoughts and emotions ([1] p 521). At the same time, it requires a willingness to be present with others' emotions and embodied experiences, to approach respectfully, tread carefully, and resist attempting to master differences ([1] p 521).

To create space for accessibility therefore requires creating a safer, emotionally supportive and welcoming environment that is mindful of participant and researcher vulnerability, to ensure that things otherwise unsayable can be expressed. To achieve this, Boydell et al. suggest that researchers fulfil their ethical responsibility by providing advance knowledge of the potential for distress and have a plan in place to respond to participants and researchers who require debriefing and/or support [1]. 


\section{Fuzzy boundaries}

When working with arts-based research methods, researchers must be mindful that boundaries among the roles of researchers, participants, and artists can become blurred ([25] p 15). Gubrium et al. refer to this blurring of roles as "fuzzy boundaries" ([27] e 3). The potential for fuzzy boundaries is intensified in projects using arts-based research methods because researchers may spend significant periods of time engaged in fieldwork; researchers and participants may co-create products; participants may be peer researchers; and participants may share or create images in a process that requires great personal investment beyond the normal role of a research participant ([25] p 15). Additionally, art created during the research process may hold personal meaning for the participants that may not be shared or recognized by the research team. When arts-based methods are used for advocacy or community engagement projects, the creative products can serve different purposes and have different meanings for all those involved ([25] p 15). This blurring of boundaries creates ethical challenges, such as how to best exit from the project when participants have invested deeply in building relationships and contributing to the research ([25] p 15).

The collaborative nature of arts-informed research, including that which is drama-based, exacerbates the potential for fuzzy boundaries, raising questions regarding authorship and the hierarchical structure of the research-based theatre production itself. In the context of disability focused arts-informed research, each of these concerns has the potential to be further exacerbated by the subject matter of a play about disability, which itself is situated within systems of oppression, systematic discrimination, 
and stigmatization ([31] p 23). As other arts-based researchers have noted, tensions may emerge between the potentially competing aims of mitigating risks of misrepresentation and of producing a research product, that has aesthetic merit and audience appeal ([29] p 465). However, in a project seeking to challenge perceptions of disability, aesthetic and artistic urges may have to remain a secondary consideration to the research objectives.

Researchers working with visual methods such as digital storytelling similarly risk fuzzy boundaries. It has been noted that digital storytelling is not a series of steps that leads to a complete story and standard outcomes; rather, it is an embedded practice, one that happens within institutions and is mediated by institutional values and discourses ([26] p 627). Digital storytelling participants are thought to actively construct their own stories. Facilitators, funders, and researchers are often absent in reports, even though they are more than merely "midwives to stories" ([27] e 5). Facilitators often help participants find a story that is neither "too easy" nor "too painful" to tell ([27] e 5), shaping stories into those that will resonate and capture the attention of viewers.

As Cox et al. [25] suggest, it is important to clearly articulate and plan for fuzzy boundaries, and to recognize that such plans will be project and context specific ([25] p 16). When working with arts-based methods, researchers might consider how different roles are defined and anticipate how they can become blurred ([25] p 17). Salient here is the ability to recognize and respond to the impact that blurred roles can have on the ethical conduct of the research ([25] p 17). At the outset of a project researchers might also consider questions such as the following:

- how different roles and perspectives are defined and articulated; 
- whether all participants understand their roles in relation to the overall project;

- if the roles that participants/researchers/others play become blurred;

- how researchers will recognize and respond to this;

- and what impacts blurred roles might have on the ethical conduct of the research, particularly with regard to concluding the project in an ethical manner ([25] p 17).

At Project $\mathrm{Re} \cdot \mathrm{Vision}$, team members strive for openness, transparency, and a willingness to work in a collaborative manner in order to navigate these fuzzy boundaries.

\section{Staring and staring back}

Garland-Thomson [32] writes that the "history of disabled people in the Western world is in part the history of being on display, of being visually conspicuous while politically and socially erased." Indeed, non-normative bodies have been, and continue to be, a "cause for pause and consideration" ([33] p 2), a "site of public spectacle" ([34] p 10), and the cause of "commotion" in public spaces ([33] p 2).

An encounter with disability often elicits surprise, attracting the attention of curious passersby who must resist the urge to stare ([33] $p 2$ ). The disabled body is "novelty writ large for the captivated starer," inciting persistent curiosity and prompting the question "what happened to you?" ([35] p 31) Staring, Garland-Thomson explains, is a more emphatic form of looking than glancing, glimpsing and other forms of casual or disinterested looking ([35] p 30). It is an urgent effort to understand the unexpected ([36] p 15). Non-normative bodies thus summon the stare, and the stare in turn 
demands a story: an "apologia that accounts for its difference from unexceptional bodies ([37] p 334)."

Arguably, the strongest staring prohibition surrounds groups who are considered different, who are the most unanticipated. Perhaps the most censured form of staring, then, is looking at individuals with disabilities ([35] p 31). As Garland-Thomson notes, starers incessantly "gawk with ambivalence or abandon at the prosthetic hook, the empty sleeve, the scarred flesh, the unfocused eye, the twitching limb" in search of a narrative that restores order in their disrupted world ([35] p 31). In this way, the disabled body is both the "to-be-looked-at" and "not-to-be-looked-at" ([35] p 31). Garland-Thomson [2] suggests that the stare is the gesture that "creates disability as an oppressive social relationship" ([2] p 26), whereby the stare confers agency upon the starer and stigmatizes the stare ([35] $p$ 32).

Why, then, would a person with a disability - who knows intimately that resisting and deflecting the stare is a part of his or her daily life deliberately invite the stare through participation in arts-based research? A survey of disability arts literature suggests that methods such as digital storytelling and drama performances critically appropriate the stare ([34] $p$ 12). In disability arts, the disabled body itself becomes a critical aesthetic medium, rather than the object of charity, medical diagnosis, or sideshow entertainment ([35] p 33). Here, staring operates as a charged social exchange between two (or more) active agents, allowing individuals to become primary makers of meaning, controlling the terms of the encounter rather than being passively on display ([35] p 32). 
Indeed, altering the staring dynamic through arts-based disability research has great potential to empower participants and transform dominant understandings of impairment. However, ethical dilemmas that arise when communicating intimate experiences in an embodied manner cannot be neglected. Boydell et al. [4] report that actors' and other artists' experiences of depicting suffering and violence remain relatively unexplored ([4] p 11). Boydell et al. found that using dance to communicate the experience of psychosis had unintended effects on the participantdancers, many of whom had experienced mental health issues themselves ([4] p 11).

Likewise, digital storytelling can create types of harm that may be unforeseen or are beyond the harmful experiences typically considered by ethics committees ([25] p 11). Cox et al. [25] note that this is especially the case when such methods engage marginalized communities in telling stories about their lives ([25] p 11). Asking participants to produce visual material when conducting arts-based disability research often results in images that portray emotionally difficult experiences. Accordingly, researchers must be mindful of the potential harms of their research, ensuring that the research is respectful and supportive, and not intrusive for participants ([25] p 12).

Lastly, critically appropriating the stare through digital storytelling and drama performance complicates the traditional assumption that researchers will protect the identity of research participants through anonymity and confidentiality. However, in visual and performance-based projects, it may be impossible - and even undesirable - to protect the privacy of individuals ([38] p 86). Maintaining visual identity is a central 
aspect of making a political statement about a group, particularly in the case of individuals with disabilities whose bodies have historically been turned into spectacles or hidden from view ([39] p 48). Indeed, if the central purpose of the research is to empower individuals and provide a venue where they can speak to the community, then to insist on anonymity and confidentiality inappropriately contradicts this goal ([25] p 10). Nevertheless, there may outside pressure from multiple stakeholders to uphold anonymity and confidentiality principles. Cox et al. [25] confirm that some research ethics boards demand total privacy, rather than giving participants the choice to be public ([25] p 10). Wiles et al. [39] contend that enabling participants to make their own informed decisions is of the utmost importance. This requires researchers to explain clearly how, when, and where data will be used and disseminated ([39] $p$ 146).

\section{The problematic of audiences}

Researchers must also consider the safety of audience members who may experience harm when they are exposed to participants' stories. It is undeniable that artful research representations have the potential to do harm to viewers and therefore that researchers are ethically required to minimize this risk. To do this, researchers must avoid overstating the audience's vulnerability, and anticipate their concerns and expectations; this includes a consent-heavy process up front with available follow-up supports ([29] p 462).

Visual products, in particular, may be both confronting and highly personal: while it can be empowering participants to share their stories, it also can be distressing to researchers and audiences ([25] $p$ 11). This can often be unexpected and unforeseen, highlighting the need for a reflexive 
and iterative approach to reduce harm that goes beyond the initial planning stages of the research ([25] p 11). In reflecting on their viewing of Project Re・Vision digital stories, $17 \%$ of participants reported feeling "unsettled," while $11 \%$ felt "concerned" and $28 \%$ were left "questioning" [40]. In a few instances, participants described feeling "depressed" and even "vulnerable" [40]. However, it would be a mistake to assume that the potential of the narratives to evoke difficult feelings constitutes a wholly negative response or even that these sorts of emotional reactions should necessarily be interpreted as "negative". The same is true of the apparently positive responses to $\mathrm{Re} \cdot V i s i o n ' s$ digital outputs, including $89 \%$ of participants who reported feeling "inspired," and others who described feeling "powerful," "courageous," and "reflective" [40]. While the negative responses of audience members might signify difficult knowledge is being communicated and that learning is occurring, the positive responses might indicate a reading into the work of dominant tropes of disability as a source of inspiration.

The intersection of art, audience, and venue is an ethically complex place ([29] p 462). As Cox et al. [25] insist, researchers have an ethical responsibility to ask themselves how they will protect audience members from visual methods that are potentially confronting ([25] $p$ 12). This is especially important as venues are often in community settings where it may be difficult to withdraw from participation ([29] p 462). Gubrium et al. [27] believe that researchers and practitioners have an obligation to inform viewers of content prior to a screening, prepare them to watch highly sensitive content by offering information about self-care, and debrief story screenings so that viewers who may have been unsettled or deeply 
affected by difficult content have a chance to share their feelings and achieve closure before leaving an event ([27] e 8).

Drama performances similarly have the inherent risk of potentially harming its audience members. Research suggests that words expressed and received "in the flesh" are even more powerful than words read on paper ([24] p 25). Mitchell et al. [24] report that after viewing a researchbased drama about individuals living with dementia, audience members described being "jolted," "shaken," "hammered," "hit," "slapped," and "crushed" by the performance ([24] t 26). One participant even used the metaphor of a machine gun, with each message piercing the body ([24] $\mathrm{t}$ 26). As Mienczakowski and Moore (2008) assert, it is important for researchers to take ethical responsibility for a range of unintended outcomes that may arise as an emotional response to a performance ([28] p 454).

The potential for these responses was evident in reactions to Re Vision's Small Acts of Saying. Following the performance, audienceparticipants reported feeling "overwhelmed," "emotional," "insulted," "unprepared," and "confused" [41]. While majority of participants left feeling "inspired" (54\%), the emotional proximity and persuasiveness of arts-based research left 26\% feeling "unsettled," 48\% "questioning," and 29\%, "concerned" [41]. This highlights the potential for arts-based research to be troubling, unsettling, and disturbing at times to those involved ([4] p 11).

Indeed, as philosopher Grosz [42] suggests, artistic representations may operate at a different register than scientific ones - that demand that we predict and proscribe certain preferred ways of being - by opening up emergent, unpredictable alternatives for knowing difference. While 
intensifying qualities of disability through art may bring about something new, it is also risky since what it generates cannot be foreseen. Accordingly, researchers using arts-based methods must be proactive and take the necessary steps towards minimizing harm. Opportunities for audiences to debrief or "talk back" to arts-based representations can be useful to understand and work through their reactions; post-performance discussions, writing spaces, notebooks, and email contacts allow researchers to understand how audiences are engaging with and affected by the representation ([29] p 463).

\section{Interpretation and the potential for (mis)representation}

Reflecting on audiences and their reactions to arts-based research raises important ethical issues regarding interpretation and the potential for misrepresentation. In staging a dramatic reading, Sinding et al. [23] have considered questions that researchers might ask themselves in preparation for guiding audience interpretation of their work: should a narrator be present to summarize and analyze the work, or should the stories be presented without commentary and rely on audience interpretation? Further, how do researchers imagine their audiences and what they want for audience members ([23] p 32)? The researchers note that even the process of selecting which narratives to present to an audience raises complex issues of voice and risks silencing perspectives ([23] p 33). In this way, when deciding which experiences will be portrayed, researchers must be mindful about how these representations might challenge and/or reinforce broader cultural stories ([23] p 33).

Daniels [42] similarly warns of the potential to misrepresent those who created the artistic work, as well as those who are depicted in their 
work ([43] p 128). Visual methods are inherently ambiguous with their meanings constantly negotiated by the viewer ([43] p 128). The viewer's perception of what is seen is influenced by various and multiple contexts, such as his or her historical or sociocultural context ([43] p 128).

Wiles et al. [39] note that when conducting arts-based research, "harm" to participants tends to take the form of embarrassment or anxiety over how representations will be interpreted ([39] p 50). From their own experiences, Wiles et al. found that a key concern of research participants was that their artistic products should not be "psychologized" by researchers as this had the potential for humiliation ([39] p 50). Researchers must be mindful of this concern in the disability context, where participants are all too familiar with having their bodies - and lives - subject to the medical gaze of others. Janna Brown, a Re-Vision participant, reflects upon the fears and vulnerabilities that encompass sharing her disability experience with others. In her untitled digital story, Janna describes the pain in witnessing her narrative undergo both scrutiny and transformation in the hands of medical professionals: her story, she explains, remained "trapped in boxes, checked, and recorded." Only when she had the opportunity to weave together her experiences into her own narrative, did she feel "wholeness."

When constructing counter stories of disability, Scully suggests that the morally preferable identity narratives are those that enhance the moral agency of the people they involve ([3] p 129). In order to enhance moral agency effectively, the story must be as faithful as possible to people's experiences. The end ethical goal is that counter stories should displace more damaging portrayals and insert ones that are missing ([3] $p$ 129). As 
Lambert [44] stresses, individuals who have faced systematic forms of discrimination and oppression must be supported in telling their own story in their own way and to the audiences they choose ([44] p 117). As such, researchers must take necessary steps to ensure that participant stories are not being misrepresented.

At Project Re $\cdot V i s i o n$, we believe that revisioning is important because we live in a world filled with (mis)representations of disability, one with which disabled artists, activists, and scholars must contend ([1] p 516). While we consider self-representation to be a powerful part of the disability rights and arts and culture movements, $\mathrm{Re} \cdot \mathrm{Vision}$ also recognizes that such representations may create a single, one-dimensional counter story to dispute the dominant narrative of disability, potentially creating a simplistic stereotypic account that may be untrue and incomplete ([1] p 516). Our goal is to move past the single story that collapses the diversity of experience and replace it with a multiplicity of stories that proliferate disabled people's voices and experiences. In this way, Re•Vision contributes to the continuous process of revisioning disability and of weighing the possibilities and limits of all representations ([1] p 519).

\section{Conclusion}

Walker-Bynum [45] writes, "shape carries story:" shape or body is "crucial, not incidental, to story ... it makes story visible; in a sense it is story." Drawing upon Bynum's claim, Garland-Thomson [46] tells us that "shape structures story is the informing principle of disability identity," and that the stories told of disability are not typically "pretty one[s]" ([46] p 114). However, as Garland-Thomson suggests, the stories of despair, 
catastrophe, and relentless cure-seeking that our culture tells about disability can be retold ([46] $p$ 114).

The digital stories created through $\mathrm{Re} \cdot \mathrm{Vision}$ experiment with a variety of mediums, including photography, film, poetry, digital art, painting, drawing, and sound in order to refigure the corporeal in our social imagination and thus re-signify the meaning of disability and other forms of embodied difference ([1] p 524). Similarly, Re•Vision's research-based drama, Small Acts of Saying, celebrates the power of bodies beyond the "norm". Disabled bodies, Scully suggests, have the potential to produce new ways of knowing shaped by embodiment that are distinct from the ways of knowing that a non-disabled body develops as it interacts with a world built to accommodate it. In this way, "thinking through the variant body" can be a resource ([3] pp 83-85).

By embracing complexity, through arts-based research, we bring the margins to the center, and create space to change our perceptions of disability and our bodies ([1] p 524). This leads to unpredictable ethical dilemmas that have seldom been explored. As theorized in this paper, artsbased disability research raises unique ethical conundrums that require careful consideration from researchers interested in this breakthrough work. As we challenge reductive scripts about the body, ability, and normality, we hope to positively construct the "shape we think of as disability."

\section{Disclosure of interest}

The authors declare that they have no conflicts of interest concerning this article. 


\section{References}

1. Rice C, Chandler E, Harrison E, Liddiard K, Ferrari M. Project Re・Vision: Disability at the Edges of Representation.

Disability \& Society. 2015 May; 30(4): 513-527. doi:

$10.1080 / 09687599.2015 .1037950$

2. Garland-Thomson R. Extraordinary Bodies: Figuring Physical Disability in American Culture and Literature. New York: Columbia University Press, 1997.

3. Scully JL. Disability Bioethics: Moral Bodies, Moral Difference. United Kingdom: Rowan \& Littlefield Publishers Inc; 2008.

4. Boydell KM, Volpe T, Cox S, Katz A, Dow R, Brunger F, Parsons $\mathrm{J}$, et al. Ethical challenges in arts-based health research. IJCAIP [Internet]. 2012 [cited 2015 Jun 29]; 11: 117. Available from: http://www.ijcaip.com/archives/IJCAIP-11paper1.pdf

5. Thomas C. Sociologies of Disability and Illness: Contested Ideas in Disability Studies and Medical Sociology. New York: Palgrave Macmillan; 2007.

6. Garland-Thomson, R. The case for conserving disability. 2012 Jul; 9(3): 339-355. doi: 10.1007/s11673-012-9380-0

7. Sandell R, Dodd J, Garland-Thomson G, editors. RePresenting Disability: Activism and Agency in the Museum. New York: Routledge; 2010. 
8. Garland-Thomson R. Integrating disability: transforming feminist theory. NWSA [Internet]. 2002 Sept [cited 2015 Jun 29]; 14(3); 1-32. Available from JSTOR:

http://www.jstor.org/stable/4316922

9. Titchkosky T. Disability images and the art of theorizing normality. International Journal of Qualitative Studies in Education. 2009; 22(1): 75-84. doi:

$10.1080 / 09518390802581893$

10. Clare E. Exile and Pride: Disability, Queerness and Liberation. Brooklyn: South End Press; 2009.

11. Disability Arts Chronology [Internet]. Disability Arts Online; 2008 Jul [cited 2015 Jun 15]. Available from: http://www.disabilityartsonline.org.uk/Chronology_of_Disa bility_Arts

12. Allan J. Inclusive Education and the Arts. Cambridge Journal of Education. 2014 Aug; 44(4): 511-523. doi: $10.1080 / 0305764 X .2014 .921282$

13. Allan J. Encounters with exclusion through disability arts. Journal of Research in Special Educational Needs. 2005 Mar; 5(1): 31-36. doi: 10.1111/j.1471-3802.2005.00036.x

14. McNiff S. Arts-based Research. In: Knowles JG, Cole A, editors. Handbook of the Arts in Qualitative Research: Perspectives, Methodologies, Examples and Issues. Los Angeles: Sages Publications; 2008. 
15. Fraser KD, al Sayah F. Arts-based methods in health research: a systematic review of the literature. Arts \& Health. 2011 Jun; 3(2): 110-145. doi:

\section{$10.1080 / 17533015.2011 .561357$}

16. Boydell KM, Gladstone BM, Volpe T, Allemang B, Stasiulis E. The production and dissemination of knowledge: a scoping review of arts-based health research. Forum: Qualitative Social Research [Internet]. 2012 Jan [cited 2015 Jun 29]; 13(1), Art. 32. Available from FQS: http://nbnresolving.de/urn:nbn:de:0114-fqs1201327

17. Lafrenière D, Hurlimann T, Menuz V, Godard B. Health research: ethics and the use of arts-based methods in knowledge translation processes. IJCAIP [Internet]. 2012 Jun [cited 2015 Jun 29]; 11: 1-26. Available from: http://www.ijcaip.com/archives/IJCAIP-11-paper3.html

18. Clover DE. Out of the dark room: participatory photography as a critical, imaginative, and public aesthetic practice of transformative education. Journal of Transformative Education. $2006 \mathrm{Jul}$; 4(3): 275-290. doi: $10.1177 / 1541344606287782$

19. Hull GA, Katz M. Crafting an agentive self: case studies of digital storytelling. Research in the Teaching of English [Internet]. 2006 [cited 2015 Jun 29]; 41(1): 43-81. Available from NCTE: http://www.ncte.org/journals/rte/issues/v41-1

20. Stewart S, Riecken T, Scott T, Tanaka M, Riecken J. 
Expanding health literacy: indigenous youth creating videos. J Health Psychol. 2008 Mar; 13(2); 180-189. doi:

$10.1177 / 1359105307086709$.

21. Meadows D. Digital storytelling: research-based practice in new media. Visual Communication. 2003 Jun; 2(2): 189193. doi: $10.1177 / 1470357203002002004$

22. Cox SM, Kazubowski-Houston M, Nisker J. Genetics on stage: public engagement in health policy development on preimplantation genetic diagnosis. Social Science \& Medicine. 2009 Apr; 68(8): 1472-1480. doi:10.1016/j.socscimed.2009.01.044

23. Sinding C, Schwartz L, Hunt M. Staging ethics: the promise and perils of research-based performance. Canadian Theatre Review. 2011 Apr; 146: 32-37. doi:

$10.3138 /$ ctr. 146.32

24. Mitchell GJ, Dupuis S, Jonas-Simpson C, Whyte C, Carson $J$, Gillis $J$. The experience of engaging with research-based drama: evaluation and explication of synergy and transformation. Qualitative Inquiry. 2011 Apr; 17(4): 379-392. doi: $10.1177 / 1077800411401200$

25. Cox S, Drew S, Guillemin M, Howell C, Warr D, Waycott J. Guidelines for Ethical Visual Research Methods. Melbourne: The University of Melbourne; 2014.

26. Dush L. The ethical complexities of sponsored digital 
storytelling. International Journal of Cultural Studied. 2013

Nov; 16(6): 627-640. doi: 10.1177/1367877912459142

27. Gubrium AC, Hill AL, Flicker S. A situated practice of ethics for participatory visual and digital methods in public health research and practice: a focus on digital storytelling. Am J Public Health. 2014 Sep; 104(9): 1606-1614. doi: 10.2105/AJPH.2013.301310

28. Mienczakowski J, Moore T. Performing Data with Notions of Responsibility. In: Knowles JG, Cole AL, editors, Handbook of the Arts in Qualitative Research: Perspectives, Methodologies, Examples, and Issues. Los Angeles: Sage Publications; 2008.

29. Sinding C, Gray R, Nisker J. Ethical Issues and Issues of Ethics. In: Knowles JG, Cole AL, editors. Handbook of the Arts in Qualitative Research: Perspectives, Methodologies, Examples, and Issues. Los Angeles: Sage Publications; 2008.

30. Aldridge J. Working with vulnerable groups in social research: dilemmas by default and design. Qualitative Research. 2014 Jan; 14(1): 112-130. doi: $10.1177 / 1468794112455041$

31. Project Re $\square$ Vision. Transcripts, Theatre Interviews, Cast Discussions, Meeting 2; 2013 Dec.

32. Gardland-Thomson R. The Politics of Staring: Visual 
Rhetorics of Disability in Popular Photography. In: Snyder SL, editor. Disability Studies: Enabling the Humanities. New York: Modern Language Association; 2002.

33. Sandahl C, Auslander P, editors. Bodies in Commotion: Disability and Performance. Ann Arbor: University of Michigan; 2005.

34. Eisenhauer J. Just looking and staring back: challenging ableism through disability performance art. Studies in Art Education. 2007 [cited 2015 Jun 29]; 49(1): 7-22. Available from ERIC: http://eric.ed.gov/?id=EJ875583

35. Garland-Thomson R. Dares to Stare: Disabled Women Performance Artists and the Dynamics of Staring. In: Sandahl C, Auslander P, editors. Bodies in Commotion: Disability and Performance. Ann Arbor: University of Michigan; 2005.

36. Garland-Thomson R. Staring: How We Look. New York: Oxford University Press; 2009.

37. Garland-Thomson R. Staring back: self-representations of disabled performance artists. American Quarterly. 2000 Jun; 52(2): 334-338. doi: 10.1353/aq.2000.0024

38. Clark A, Prosser J, Wiles R. Ethical issues in imagebased research. Arts \& Health. 2010 Mar; 2(1): 81-93. doi: 10.1080/17533010903495298

39. Wiles R, Coffey A, Robinson J, Heath S. Anonymisation and 
visual images: issues of respect, 'voice' and protection. International Journal of Social Research Methodology. 2011 Jun; 15(1): 41-53. doi: 10.1080/13645579.2011.564423

40. Project Re•Vision. Survey Data, St. Joes; 2013 and 2014.

41. Project Re•Vision, Survey Data, Trent; 2013 and 2014.

42. Grosz E. Chaos, Territory, Art: Deleuze and the Framing of the Earth. New York: Columbia University Press; 2008.

43. Daniels D. Exploring Ethical Issues When Using Visual Tools in Educational Research. In: Liamputtong $P$, editor. Doing Cross-Cultural Research: Ethical and Methodological Perspectives. Berlin: Springer; 2008.

44. Lambert J. Digital Storytelling: Capturing Lives, Creating Community. 4th ed. New York: Routledge; 2013.

45. Bynum CW. Shape and Story: Metamorphosis in Western Tradition. National Endowment for the Humanities Jefferson Lecture in the Humanities. Concert Hall of the Kennedy for the Performing Arts, Washington; 1999 Mar 22.

46. Garland-Thomson R. Shape structures story: fresh and feisty stories about disability. Narrative. 2007 Jan; 15(1): 113-123. doi: 10.1353/nar.2007.0005 